\title{
Türkiye'de Okul Öncesi Ë̆itimi'nde En Çok Kullanılan Çocuk Şarkılarının Notalarının, Çocukların Yaşlarına Uygunluğunun Değerlendirilmesi Ve Şarkıların Türk Dili Prozodi Kurallarına Göre İncelenmesi ${ }^{1}$
}

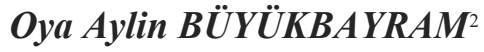 \\ Leyla PINAR TANSEVER
}

Öz

Okul öncesi dönemdeki çocukların gelişimsel süreçlerinin doğru ilerleyebilmesi gelecek nesillerin daha mutlu ve başarılı olmasını sağlayacaktır. Bu sebeple yapılan bilimsel çalışmalar çocukların gelişimsel süreçlerini kazanımlar halinde incelemiş ve bu süreçte müziğin tüm gelişimsel alanlara olan olumlu etkilerinin kanıtlanmasını desteklemiştir. Müziğin, eğitimöğretimde sürekli olarak kullanılması ise çocuk şarkılarının niteliklerine önem verilmesinin gereğini ortaya koymuştur.

Müzik, aynı zamanda iletişimi sağlayan ve konuşma dillerinden farkı olmayan ve çocuğun, kendini gerçekleştirmesine aracı olan, kültürün önemli bir basamağı ve vazgeçilmez parçasıdır. Kültürün unsurlarının, birbiri ile olan etkileşimi ve bu unsurların insanların ihtiyaçlarından ortaya çıkmış olması ise müziğin hayatımız açısından önemini açıklamaktadır.

Anadil ve müzik dilinin, bir araya geldiklerinde eğitici ve öğretici olması, çocuğun tüm yaşantısını etkileyebilecek güce sahip olması ise önce çocukların gelişimsel sürecini ve daha sonra kültür kavramını anlamamızın gerekliliğini ortaya koymaktadır.

Çocukların gelişimsel süreçte müzikten nasıl etkilendiğinin, müziğin hangi kazanımlar için kullanılabileceğinin bilinmesi, şarkı seçimlerinin doğru yapılabilmesi, okul öncesi eğitiminin daha verimli hale getirilmesi bakımından önem taşımaktadır. Müziğin, çocuk tarafında anlaşılmaya başlandığı dönemin bebeklik dönemi olması ve ilerleyen çocukluk yaşlarında kültür birikimin hızla oluşacağının bilinmesi, anadilin ve müziğin kullanılma şekline özen gösterilmesinin gereğini ortaya koymaktadır. Odak noktasının, çocuk şarkıları olması ise, Türk Dili ve müzik dilinin, aralarında ilişkilendirilmesi ve yapısal özelliklerinin doğru aktarılmasının önemini vurgulamaktadır.

Prozodi kavramının derinliği ise hem anadilden hem müzik dilinden hem de şarkılarda yansıtılmaya çalışılan duygulardan ve düşüncelerden kaynaklanmaktadır. Kurallarının doğru

\footnotetext{
${ }^{1} \mathrm{Bu}$ çalışma, Prof. Dr. Leyla PINAR TANSEVER < leylatansever@halic.edu.tr> danışmanlığında hazırlanan Türkiye'de Okul Öncesi Eğitimi'nde En Çok Kullanılan Çocuk Şarkalarının Notalarının, Çocukların Yaşlarına Uygunluğunun Değerlendirilmesi ve Şarkıların Türk Dili Prozodi Kurallarına Göre İncelenmesi başlıklı doktora tezinden hareketle oluşturulmuştur.

${ }^{2}$ El-Mek: aylinbuyukbayram@aydin.edu.tr, Orcid Id: https://orcid.org/0000-0002-2366-8287

3 leylatansever@halic.edu.tr, Orcid Id:0000-0002-7345-2193

Makale geliş tarihi / received: 11.03.2020

Makale kabul tarihi / accepted: 12.08 .2020
} 
Türkiye'de Okul Öncesi Eğitimi'nde En Çok Kullanılan Çocuk Şarkilarının Notalarının, Çocukların Yaşlarına Uygunluğunun Değerlendirilmesi Ve Şarkıların Türk Dili Prozodi Kurallarına Göre İncelenmesi

anlaşılabilmesi ve çocuk şarkılarında bulunması gereken özelliklerle söz ve sözlerin karşılarına gelen notaların sürelerin birbiri ile uyumunun incelenmesi oldukça önemlidir. Ulaşılan bilgilerin, okul öncesi eğitiminde kullanılabilir hale gelmesi, yeni nesillerin Türk kültürüne uygun yetişmesi, diğer kültürle olan iletişiminde başarılı olması, Türk kültür mirasının korunması, diğer kültürlerle etkileşimi ve gelecek nesillere aktarımı bakımından önemlidir.

Prozodi kurallarının uygulanması amacı ile seçilen şarkılar, Türkiye'de okul öncesi eğitiminde en çok kullanılan şarkılardandır. Sebebi ise yeni neslin, anadil ve müzikle ilgili durumunu öngörebilmektir. Değiştirilebilecek durumlar için yapıcı değerlendirmelerin ortaya konulması ise çocuk şarkılarının özellikleri, şarkılarda anadil ve müzik dili kullanım şekli konusunda farkındalık uyandıracaktır. Bu sebeple çocuk şarkılarının hem ses aralıklarının değerlendirilmesi hem de prozodilerinin incelenmesi, bahsi geçen konuların uygulama kısmı olarak, konuların örneklendirilerek tamamlanmasını sağlamıştır.

Anahtar Kelimeler: Okul öncesi eğitimi, kültür, anadili, şarkı, prozodi.

\title{
The Cultural Importance of the Songs Which Are Used In Pre-School Education in Turkey and Analysis of These Songs According To Turkish Language Prosody Rules
}

\begin{abstract}
The advancement of the developmental processes of preschool children will make future generations happier and more successful. For this reason, scientific studies have examined the developmental processes of children in terms of gains and supported the demonstration of positive effects of music on all developmental areas. The continuous use of music in education revealed the necessity of giving importance to the qualities of children's songs.
\end{abstract}

Music is also an important step and indispensable part of the culture that enables communication and is the means for the child to realize himself. The interaction of the elements of culture and the emergence of these elements from the needs of people explain the importance of music for our lives.

The fact that the mother tongue and music language, when they come together, is educational and instructive, and has the power to affect the whole life of the child, reveals the necessity of understanding the developmental process of children and then the concept of culture.

It is important to know how children are affected by music in the developmental process, which gains can be used for music, making song choices correctly and making preschool education more efficient. The fact that music is being understood on the child's side is a period of infancy and that the accumulation of culture will occur rapidly in the advancing childhood ages, reveals the necessity to pay attention to the use of mother tongue and music. The fact that the focus is on children's songs emphasizes the importance of associating the Turkish language and music language with each other and conveying the structural features correctly.

The depth of the concept of prosody stems from both mother tongue, music language and emotions and thoughts that are tried to be reflected in songs. It is very important that the rules 
are understood correctly and that the features that should be found in children's songs and the harmony of the periods of notes and words that come up against each other. It is important in terms of making available information available in preschool education, raising new generations in accordance with Turkish culture, being successful in communicating with other cultures, preserving Turkish cultural heritage, interacting with other cultures and transferring to future generations.

The songs chosen for the implementation of prosody rules, in pre-school education in Turkey is one of the most used song. The reason is to predict the status of the new generation in terms of mother tongue and music. Constructing constructive assessments for changeable situations will raise awareness of the characteristics of children's songs, how to use the mother tongue and music language in the songs. For this reason, both the evaluation of the sound intervals of children's songs and examining the prosody of the subject, as a part of the application of the subject, the subjects have been completed by sampling.

Keywords: Pre-school education, culture, mother tongue, song, prosody.

\section{GÍRIŞ}

İnsanın varoluşundan, bugüne ulaşan ritim ve ses olguları, insanların doğal ihtiyaçları ve ihtiyaçların sonucu ortaya çıkmıştır. İhtiyaç duyulan bilgilerin birikimi ise kültür kavramı ile açıklanabilmektedir. Kültürü oluşturan ögelerden olan iletişim kavramı ise dili ve müziği bir araya getirmektedir. Müzik, her ne kadar bir sanat dalı olarak görülse de aslında insanın doğasında her zaman var olan, gelişimsel sürecine katkıda bulunan iletişim dilidir. Eğitimöğretim alanlarında kullanılmasının en belirgin sebebi de doğa ve insanlar arasında bağ kurabilmesidir.

Ses ve ritim, müziğin ana ögelerindendir ve sesin frekanslarının, doğa ve insan arasında duygu geçişini sağladığı bilinmektedir. Bu duygu aktarımı, kimi zaman sanat kimi zaman da iletişim olarak adlandırılmıştır. İletişimin ya da sanat eserinin yansıtmak istediği duygunun gücü, iletişimin dili, dilin doğru ve verimli kullanımı ile mümkün olabilmekte; çocukluk döneminden itibaren başlayan ve ömür boyu devam edecek olan bu kültürel süreç ve aktarımın, doğanın ve insanlığın varlığı süresince de devam etmesi beklenmektedir.

İlkel çağlardan bugüne yapılan araştırmalar incelendiğinde, şarkı sözleri ile şarkıların ritmik yapılarının süre açısından ilintili olduğu fark edilmiştir. Bu nedenle ana dil ile ritmik yapıların ve seslerin ilişkilendirilmesi, duygularımızı ve düşüncelerimizi doğru aktarmanın yani dillerin kurallarına uygun kullanılmasının gerekliliği yani prozodi kuralları çerçevesinde aktarılmasının önemi gözler önüne serilmiştir. Okul öncesi çocuklarının gelişim sürecindeki bütün kazanımları bakımından önem taşıyan müzik özellikle anadil gelişimindeki anahtardır. Anadilde oluşan erozyonların önlenebilmesi, kültürümüzün ve müzik eserlerinin nesilden nesle, doğru aktarılabilmesine katkı sağlaması amacı bu çalışmanın temellerini oluşturmuştur.

Bu amaçlarla hazırlanmış Sanatta Yeterlik tezinde ve teze dayalı hazırlanmış olan bu makalede okul öncesi öğretmenliği alanında uzmanların görüşlerine başvurulmuş, okul öncesi kurumlarında çalışmakta olan öğretmenlere danışılmış ve çalışmalar bu doğrultuda literatür taraması yapılarak çalışılmıştır. Günümüzde, okul öncesi eğitim-öğretiminde kullanılan beş 
Türkiye'de Okul Öncesi Eğitimi'nde En Çok Kullanılan Çocuk Şarkilarının Notalarının, Çocukların Yaşlarına Uygunluğunun Değerlendirilmesi Ve Şarkıların Türk Dili Prozodi Kurallarına Göre İncelenmesi

çocuk şarkısı seçilmiş, çocukların kazanımları bakımından değerlendirmeler yapılarak, kültürle ve anadille ilişkilendirilerek incelemeler yapılmıştır. İncelemeler ve değerlendirmeler Türk Dili ve müzik dili kurallarının kılavuzluğunda ve bu dillerin birbirleri ile ilişkilendirilmesi ile ortaya konulmuştur. Çalışma süresince edinilen bilgilere, literatür tarama yöntemi ile ulaşılmış, uzman görüşleri yardımı ile seçilen şarkılar, bilgiler ışığında değerlendirilmiş̧ir. (Yıldırım ve Şimşek, 2018).

\section{2. ÇOCUKLARDA MÜZIK, MÜZIK EĞITTIMI VE ÖNEMI}

Çocuğun doğmadan önce, anne karnında geçirdiği süreçte, çevreden duyduğu müzik ve birikimi ile başlayan süreç, çocuk, doğmasını, hayata gözlerini ilk açması ile birlikte, doğa ve etrafındaki insan ve diğer canlılarla ilk ilişkileri seslerle kurmaktadır. Bu husus bütün çocuklarda doğuştan gelen ihtiyaçtan, müziğe karşı ilgi ve yeteneğinden kaynaklanmaktadır. Sesi ve ritmi, sözlerinin verdiği duyguyu algılayabilen çocuk, aşina olduğu bu bildirim yöntemi ile de diş dünyayı öğrenme sürecine uyum sağlamaktadır. Çünkü müzik; insanın doğasında, duygu ve düşüncelerini sesle anlatmaya yarayan uluslararası bir sanat dalıdır ve doğadaki her şey üstünde etkisi bulunmaktadir.

Ayrıca müzik, öğrenmenin daha eğlenceli ve kolay bir şekilde yapılmasına olanak sağlar. Oyunlarda müziğin kullanılması da müziğin eğlenceli olmasından kaynaklanmaktadır. Müzikli çocuk oyunlarının, eğitim-öğretimde kullanılması da çocukların eğlenerek öğrenmesini sağlamak amacı iledir. Müziğin insan yaşamındaki etkileri incelendiğinde, kişinin özgüvenle hayatına devam edebilmesi ve mutlu olabilmesi için gerekli alt yapıyı sağladığı görülmektedir. Yaratıcı zekânın gelişmesi ile problem çözme yeteneği kazanan bire iler hayatlarında daha başarılı hale gelmektedir. Sesin ve ritmin kavranması daha duyarlı bire iler hale gelinmesini sağlar, müziğin insan sağlığı için kullanılması ve stresi tedavi etmesi de bilinen gerçeklerdendir.

Farklı müzik türleri ile iç içe olmak bireylere farklı bakış açıları kazandırmaktadır. Topluluklar içinde iletişimin gelişmesini ve bağların kuvvetlendirilmesini destekleyen müzik, ortak dil olarak, karşılıklı duygudaşlık ve anlayış becerisinin oluşmasını sağlamaktadır. İnanışların kökenlerine bakıldığında karşımıza çıkan ilahilerin, ritüellerde kullanılan enstrümanların, mantraların ve duaların müzikle olan bağı yadsınamaz bir gerçektir. İnsanların çocukluktan itibaren müzikle ilgili çalışmalarını sürdürmeleri bu sebeple kültür ve iletişim bakımından da önem taşımaktadır.

"Okulöncesi dönemde yapılan müzik çalışmaları göz önüne alındığında; müzik eğitiminin esas hedefi, okul öncesi çocuğunun gelişim alanlarında kazanım üretmek olduğu görülmektedir.” (Dinçer, 1992; Modiri, 2012).

Çocuğun müziği, anadil ile ilişkilendirerek öğrenmesini gerektiren bu gelişim türü, beden dili ve anadil ile birleştirilerek öğretildiğinde, özellikle anadilini doğru öğrenmesi sağlanmış olacaktır. Ayırt etme, benzetme ya da ayrıştırma becerisinin kazanılması, harflerin özelliklerinin idraki ve doğru kullanılmasını desteklemektedir. Bu kazanımların sağlanmasını destekleyen en önemli müzik türü de müzikli çocuk oyunları olarak karşımıza çıkmaktadır (Kol, 2011; Modiri, 2012; Sığırtmaç, 2005). 
Müziğe vücut dili ile eşlik edebilme, el ve kol hareketleri ile tepki verebilme, şarkılara eşlik edebilmek için yüz kaslarını kullanma şeklinde görülen motor gelişimi ise kaslarla ilintili gelişim alanıdır.

Ayrıca çalgı ve koordinasyon çalışmalarında el göz koordinasyonlarının, şarkı söylerken dolaşım ve solunum sistemlerinde aktif olarak değişikliklerin tespiti çocukların büyüme ve gelişmelerinin desteklenmesi ile fiziksel büyümede, müziğin etkilerini gözler önüne sermektedir (Artan, 2015; Sığırtmaç, 2005).

Zihinsel beceri ve yaratıcılık bireylerin hafıza, akılda tutma, kayıtlı bilgileri başka bir alanda ya da yeni bir durumda kullanılması bakımından önem taşımaktadır. Bilgiler arasındaki geçişkenliği görebilme ve ilişkilendirme, zihinsel gelişimin sonucu olarak karşımıza çıkmaktadır. Yapılan araştırmalar ve bilişsel gelişme ile ilgili çalışmalar, bu gelişimin, çocuklar açısından, müzik eğitimi ile paralel geliştiğini göstermektedir.

Bütün bu sebeplerden çocuklara çok küçük yaşlardan itibaren müzik eğitimi verilmesi, toplumun kültürel gelişmişlik seviyesini de yükseltecektir. Çocuklara verilecek eğitimler konusunda bilinçli olmak için çocukların gereksinimlerini de anlamak gerekmektedir (Artan, 2015; Ömeroğlu ve diğ., 2006; Sı̆̆ırtmaç, 2005).

Bireyin kendisini bir sosyal grubun, bir topluluğun üyesi olarak hissetmesi ancak müzikle sağlanabilir. Çocukların bir grubun üyesi olarak hissetmesi onda bir haz uyandırmanın yanı sıra birbirlerine sayg1 göstermelerini sağlar ve en önemlisi öğretir. Topluluğun diğer üyeleri ile düşüncelerini paylaşmayı, işbirliği yapmayı, sıra beklemeyi öğrenir. Çocukların ufkunu açar, kendilerine duyduğu özsaygıyı arttırır.

$\mathrm{Bu}$ amaçlarla çocuklar kendi doğasına bırakılmalı ve yaratıcılık gelişiminin desteklenmesi bakımından müziği dikkatle dinlemesi, odaklanabilmesi için uygun ortam sunulmalıdır (Artan, 1993; Artan, 1995; Sı̆̆ırtmaç, 2005).

\section{MÜZİK, KÜLTÜR VE ANADİL İLISSKISII}

İnsanlar doğduklarında algı süzgeçleri oluşturmaya başlamaktadır. Algı süzgeçleri, bebeklikten itibaren, çevrelerin etkisi ile ve bilgi birikimi vasıtası ile şekillenmekte, zaman içerisinde duyguları, düşünceleri, gelenek-göreneklerin farkındalıklarını, tüm ihtiyaçlarını, yaşayış şekillerini belirlemektedir. Kültürel tercihlerin nasıl yapılacağı ve ihtiyaçların nasıl karşılanacağı konusunda oluşturulan kriterlerine ise yine alg1 süzgeçleri yol göstermektedir.

Kültür kavramı sosyal bağlamda değerlendirildiğinde ise tek bir değişkene bağlı değişime ve gelişmeye uğramadığı, bu değişkenlerin birbirinden bağımsız tanımlanamadığı ortaya çıkmaktadır. Maddi ve manevi değerlere sahip olan insan, çağlar boyunca sürdürdüğü kültürel alışkanlıkları yine bu değerlerin birbiri ile ilişkisi ve kültürlerin devamlılı̆ğ ile benimser hale gelmiştir. Bu sebeple kültür kavramının özelliklerini ve unsurlarını; toplum kültürünü ve kültürlerin nasıl yayıldığını ve benimsendiğini anlayabilmek açısından iletişim bağlamı ile kültürü incelemek gerekmektedir (Adorno, 2011; Candan, 2008; Cook, 1999; Günay, 2011; Güvenç, 2010; Karaağaç ve Yavuzer, 2011; Kaygısız, 2017; Korkmaz ve diğ., 2005; Wulf, 2009; Yakıcı ve diğ., 2010; Yıldırım ve Koç, 2011). 
Türkiye'de Okul Öncesi Eğitimi'nde En Çok Kullanılan Çocuk Şarkilarının Notalarının, Çocukların Yaşlarına Uygunluğunun Değerlendirilmesi Ve Şarkıların Türk Dili Prozodi Kurallarına Göre İncelenmesi

Kültürün tanımlarına bakıldığında, sürekli olarak, topluluk, toplum, millet, vb. kavramlarla karşılaşmaktayız. Bebeklikten itibaren içinde yer alınan topluluklar, ilk yakın çevre olan aile ile başlamakta ve yaşamı boyunca birçok farklı topluluklara dahil olunarak sürdürülmektedir. Dolayısıyla öğrenilen kültür farklı gruplara da ister istemez aktarılmaktadır. Bu sebeple kültürün unsurlarını ve bu unsurların iletişim yolu ile aktarımını incelemek gerekmektedir. Aktarımın ortak dille yapıldığını yadsımak imkânsızdır ve kültürün unsurlarını iletişim bağlamında değerlendirebilmek önem arz etmektedir (Adorno, 2011; Candan, 2008; Erol, 2009; Güvenç, 2010; Karaağaç ve Yavuzer, 2011; Korkmaz ve diğ., 2005; Wulf, 2009; Yakıcı ve diğ., 2010; Şentürk, 2016).

Kültürün birbirinden bağımsız düşünülemeyecek unsurları, toplumların, milletlerin karakterlerini, yaşayış biçimlerini, dünya algılarını, düşünce yapılarını; insan olgusunun yaradılışından olan tüm ihtiyaçları ve iletişim alanlarını kapsamaktadır. Ait olduğu milletin genel davranış kalıplarını yansıtan gelenek-görenekler, giyim tarzları, yemek türleri "folklor" başlığı altında incelenirken, toplu yaşam şartlarına uyum sağlamak ve düzeni korumak için doğal süreçte oluşan hukuk kuralları, başka bir deyişle örf ve adetler olarak tanımlanabilmektedir. Zamanla oluşan din ve ahlak kurallarının da davranış kalıplarının şekillenmesinde önemli rol oynadığı, bütün bu kültür birikimlerinin coğrafi konumlanış, siyasi görüş, ekonomik şartlar, felsefi düşünceleri ve tüm psikolojik unsurlar ile süreklilik arz ettiği görülmüştür. Bütün bu unsurlar kişiden kişiye, topluluklar veya milletler içerisinden diğerlerine aktarımı iletişim yöntemleri sayesinde sağlanabilmektedir.

Kültürün en önemli unsurlarından bir diğeri ise sanattır. Hatta unsur olmakla kalmayıp iletişimin kendisini gerçekleştirmektedir. Resim, heykel, mimari, sinema, tiyatro, dans ve özellikle müzik gibi sanat dalları, anadil ve diğer dillerle birleştiğinde kültürler, yeryüzünde uluslararası boyuta ulaşmaktadır.

Sanatsal iletişim kavramı da bu süreçlerin anlamlandırılabilmesi bakımından önem taşımaktadır. Kültür birikiminin, oluşum süreçlerinin uyum içinde ilerlemesi, benzerliklerin ortaya çıkmasında, toplulukların homojen olmayan yapılarının da sürecin değişkenlerinin içinde değerlendirilmesi gerekmektedir. Oluşan kültürler iletişim kanalına girdiğinde gözlenen durum, iletişimin de süreç içerisinde değerlendirilmesinin gereğini ortaya koymaktadır. Örneğin ilkel çağlardan bugüne aktarılan ritüellerde inanışlar, düşünceler ve duygular, dans ve müzik yolu ile aktarılmıştır. İnançlar, toplulukların ortak bilinci düşünceler, duygular arasında köprü oluşturmuş̧tur. Düşünceler bu süreçte bilgi birikimine dönüşmekte ve dil, özellikle anadili kavramı önem kazanmaktadır. Çünkü sanat dalları ile anadil, bir araya gelerek bütünün parçalarını oluşturmaktadırlar. Bütün bu sebeplerden dilin kullanımı ve sanatsal iletişimin gücü, toplumlar / milletler için oldukça önem taşımaktadır (Adorno, 2011; Candan, 2008; Güvenç, 2010; Karaağaç ve Yavuzer, 2011; Korkmaz ve diğ., 2005; Wulf, 2009; Yakıcı ve diğ., 2010).

İnsanlığın varoluşu ile ortaya çıkan ilk ihtiyaçlara, bilgi birikimlerine iletişim araçlarına ve ilkel çağlardan bugüne aktarılan tarihsel çalışmalara hem geçmişi hem bugünü aydınlatan temel olgulara bakıldığında iletişim, dil ve sanat kavramlarının ilişkilendirilerek anlatıldığ görülmektedir. Birbirinden ayrı düşünülemeyen bu kavramlar yüzyıllar içerisinde birbirlerinin gelişimlerini desteklemiş ve nesiller arasında köprü görevi görmüştür. 
Bireylerin duygularını ve düşüncelerini, içlerinde, anadilleri ile tekrarlamaları, tartışmaları, ölçüp, tartıp üslup seçmeleri de duyguların düşüncelerin anadilden bağımsız ifade edilemeyeceğini göstermektedir. Sanat kavramının kökenine bakıldığında ise duygu ve düşüncelerin aktarımının din, dil, ırk ayırt etmeksizin, kimi zaman ortaya konulan eserlerle kimi zaman beden dili yani devinimsel, yaratıcı hareketlerle kimi zaman sesler ve dil vasitası ile sağlandığı anlaşılmaktadır. Hepsinin ortak özelliğinin, insan ihtiyacının da iletişim ve kendini gerçekleştirme arzusu olduğu yadsınamayacak bir gerçektir.

"Eski tarihlerde yaşamış insanlara göre sezgi her şeyin temelinde yer alırdı ve müzik, herhangi bir mekanik bilim veya sanat olarak görülmezdi. Onların açısından müzik, insanların kullandığı ilk lisandır" (Khan, 2001:43).

Bütün bu sebeplerden, kültür, müzik, dil, anadil ve iletişim birbirinden ayrı değerlendirilemeyeceği, bir bütün oldukları ve sürece bağlı olarak beraber geliştikleri açıkça görülmektedir. Anadilin, kurallarına uygun kullanılabilmesi, beden diline ve diğer tüm etki alanlarına doğru yansıtılması, uluslararası kodlara çevriminin gerçeği direk yansıtması ise dünya üzerindeki bütünleşmenin sağlanmasında önemli rol oynamaktadır (Adorno, 2011; Altıntaş ve Çamur, 2013; Campbell, 2006; Candan, 2008; Güvenç, 2010; Karaağaç ve Yavuzer, 2011; Khan, 2001; Korkmaz ve diğ., 2005; Oskay, 2011; Wulf, 2009; Yakıcı ve diğ., 2010).

\section{Türk Dili’nde Prozodi}

Sosyal bir camlı olan insan, hayatını, toplum kurallarına, zamanın getirdiği gelişmişlik düzeyine, yaşantısına göre düzenlese de doğa ile olan bağı her zaman devam etmektedir. Seslerin doğadaki varlığı, insanların duyguları ve düşünceleri ile şekillendirildiğinde ise müzik olgusu karşımıza çıkmaktadır.

Müziğin, anadil ve diğer diller kadar güçlü iletişim bağı oluşturabilmesi, kendisinin uluslararası olma özelliğinden, sürekli ve yaygın kullanılmasından kaynaklanmaktadır. Her dil gibi müzik dilinin de ögeleri, yapı özellikleri, yapısına özgü kuralları vardır. Müzik dilini bu özelliklere uygun kullanabilmek, kurallara uygun bildirim sistemi oluşturarak anadil ile birleştirebilmek oldukça önemlidir. Yapısal özelliklerin gereklilikleri yerine getirildiğinde ise dikkat edilmesi gereken başka unsurlar ile karşılaşılmaktadır. Özgünlük ve estetik değerler, bu iletişim sürecini destekleyen, kuvvetlendiren önemli kriterler olarak göz önünde bulundurulmalıdır.

\subsection{Prozodi Kavramı}

Tınıları anlatan seslerin ve seslerin sürelerinin ifade edilmesinde kullanılan sürelerin yani ritim kavramının doğru incelenebilmesi, sözün yer aldığı eserler için de bu ögelerin anadil ya da dil ile doğru birleştirilebilmesi önemlidir. Estetik değerlerin de arka plana atılması mümkün olmayacaktır. Dolayısıyla eserlerde kullanılan iki dilin yani müzik dilinin ve sözlerin dilinin birbiri ile uyumlu olması gerekmektedir.

Müzik dilindeki ritim kavramının süre konuşma dillerindeki kelimelerin, hecelerin süreleri ile uyumlu olması, şarkılardaki notaların incelip kalınlaşmasının duygulara ve şarkıda anlatılmak istenenlere hizmet ediyor olması tesadüf değildir. Bireyler kendilerini ifade ederken nasıl doğal 
Türkiye'de Okul Öncesi Eğitimi'nde En Çok Kullanılan Çocuk Şarkılarının Notalarının, Çocukların Yaşlarına Uygunluğunun Değerlendirilmesi Ve Şarkıların Türk Dili Prozodi Kurallarına Göre İncelenmesi

bir yol izliyor; beden hareketlerine, ses tonlarına, konuşma hızlarına, vurgularına dikkat ediyorlarsa şarkı icrasında da aynı anlatım biçiminin korunmasını sağlamalıdırlar.

Anadilin estetik kurallarına uyulmasının gereği bilinmektedir ve müzik dili anadilden bağımsız düşünülemez. Dolayısıyla müziğin unsurlarını, anadilin unsurlarını, anlatım biçimlerini bütünleştirebilmek için kurallar bütünü ortaya çıkarılmıştır. Prozodi olarak tanımladığımız bu bütünlük, ilişkilendirme ve oranlama, her dilin yapısına göre farklılık göstermektedir. Türk Dili'nin prozodisini anlamak için prozodi türlerini incelemek yazı dili, okuma dili, anlam ve müzik dili prozodilerini ilişkilendirmek şarkıların özünü yani duyguları, düşünceleri en doğru halleri ile ortaya koymak bakımından önem taşımaktadır (Arel, 1997; Dinçer, 1992; Ergin, 2002; Güldaş, 1980; Güldaş, 2003; Hatipoğlu, 1988; İçelli, 2013; Karaağaç ve Yavuzer, 2011; Karahan, 2018; Korkmaz ve diğ., 2005; Say, 2005; Yakıcı ve diğ., 2010).

\subsection{Türk Dili’nde Prozodi Çeşitleri}

\subsubsection{Yazı Dili Prozodisi}

"Bir ülkede konuşulan ağızlardan birinin yazışmalar için kabul edilmiş anlatım biçimine Yazı Dili denir. Bizde yazı dili olarak, İstanbul Ağzı kabul edilmiştir.” (Güldaş, 2003, s. 201).

Okullarda öğretilen ilk okuma yazma dersleri, Türk Dili kuralları bu sebeple ortaktır ve ülke içerisindeki okullarda öğretilen kurallar bütünü aynıdır. Anlatılmak istenen duygunun, düşüncenin kaynağı ile yazılmış olanın aynı olması için Türk Dili kurallarına uymak gerekmektedir. Konuşma prozodisinden farklı ve kurallar bütününe daha sıkı bağlı olması da konuşma dili ile anlatılmak istenen anlık olarak tekrar anlatılabilecekken yazı dilinin kalıcı olmasıdır. Üstünden belirli bir zaman geçtiğinde ve tekrar okunduğunda, aynı duygu ve düşünceyi yansıtamıyorsa o zaman yazılmış olanların anlamı kalmamış olmaktadır.

Düz yazı ve şiir yazı türleridir ve bu türlerin birbirinden ayrı özellikleri olsa da ortak noktaları bulunmaktadır. Her ikisi içinde öncelikle önemli olan imlâ ve noktalama kurallarına dikkat etmek, kendi içinde uyumlu ve anlam bütünlüğüne sahip cümleler kurulabilmesidir. Düz yazılarda, anlam bütünlüğü nasıl giriş, gelişme, sonuç bölümlerinin birbirini takip etmesi ile oluşuyorsa, şiirler de aynı ahenge sahip olmalıdır.

Şiir için önemli olan başka bir özellik ise kafiye kavramıdır, ahengin oluşabilmesi için dikkat edilmesi gerekir. Ahengi oluşturan ise hecelerde kullanılan seslerdir. Sesler birleşerek heceleri, heceler birleşerek sözcükleri, sözcükler birleşerek sözcük gruplarını, sözcük ve sözcük grupları da cümleleri meydana getirmektedir. Dolayısıyla sesler arasındaki uyum, cümlenin bütününe taşınmakta, hatta cümlenin kendisinden önceki ve sonraki cümle ile anlam bütünlüğü sağlaması açısından ve anlamlı kompozisyonlar çıkması bakımından önem taşımaktadır.

Ahengin oluşması açısından sözcüklerin, sözcük gruplarının, cümlelerin incelenebilmesi için, uzun yıllardır yapılan çalışmalarla, dikkat edilmesi gereken kriterlerin, hecelerin uzunluğu, vurgu kavramları ve karşı tarafa aktarılmak istenen duygunun doğru aktarımı için tonlama olduğu ortaya konulmuştur.

Hecelerin sürelerine göre uzunluklarının belirlenmesi, uzun hecelerin ise kısa hecelere göre daha uzun sürede okunması beklenmektedir. Cümle vurgularının doğru uygulanması için ise 
noktalama işaretlerine dikkat edilmesi gerekir. Türk Dili’nin yapı kurallarına göre, vurgulanmak istenen kelime yüklemin hemen önünde bulunmaktadır. Fakat vurgulanmak istenen diğer cümle ögelerinin de noktalama işaretlerine bağlı olarak, tonlama yardımı ile vurgulu okunabileceği görülmüştür.

$\mathrm{Bu}$ durumdan anlaşılabileceği gibi yazı dili prozodisini diğer prozodi türlerinden ayrı düşünebilmek ve kullanabilmek mümkün değildir. Vurgulu ve uzatılması beklenen heceleri diğer prozodi türleri ile incelendiğinde ses ve süre kavramlarının bir arada değerlendirilebilme imkânı oluşacaktır. Bu kavramları diğer prozodi çeşitleri altında incelemek müzik dili prozodisinin de daha kolay anlaşılmasını sağlayacaktır (Arel, 1997; Dinçer, 1992; Ergin, 2002; Güldaş, 1980; Güldaş, 2003; Hatipoğlu, 1988; İçelli, 2013; Karaağaç ve Yavuzer, 2011; Karahan, 2018; Korkmaz ve diğ., 2005; Say, 2005; Yakıcı ve diğ., 2010).

\subsubsection{Konuşma ve Anlam Dili Prozodisi}

İnsanlar, yazılı şiir veya düz yazıları okurken, içinden sesli şekilde satırları tekrarlamaktadır. Vurgu ve tonlamayı yapabilmek ve anlatılmak istenenin kavranabilmesi için kelimeleri ve cümleleri, noktalama işaretleri ile anlatıma yansıtılması, aktarılmak istenen duygu ya da düşüncenin tonlamalarla ifade edilmesi, yazının seslendirilmese bile anlamlandırılmasını sağlayacaktır.

Konuşma dili beden diline yansıtıldığında da beden, sevinci, üzüntüyü, heyecanı, öfkeyi, vb. içgüdüsel olarak aktarabilmektedir. Dolayısıyla okuduğumuz düz yazı ya da şiirin, yazılması esnasında ahenk için kullanılan unsurlara dikkat etmek gerekmektedir. Aksi halde iletişim sıkıntısı yaşanabilmekte ya da yanlış anlaşılmalara sebep olunabilmektedir.

Günlük konuşmalarda, televizyon ve radyo kanallarında, günlük haberler dinlenirken veya sesli olarak yazı okunurken fark edilen bir durum daha vardır. İstanbul Türkçesi yazıldığı gibi okunan bir dil olmamasıdır. Bu sebeple yazılı eserlerde prozodi incelerken okunuşlarındaki farkl1lıklara dikkat edilmelidir (Arel, 1997; Dinçer, 1992; Ergin, 2002; Güldaş, 1980; Güldaş, 2003; Hatipoğlu, 1988; İçelli, 2013; Karaağaç ve Yavuzer, 2011; Karahan, 2018; Korkmaz ve diğ., 2005; Say, 2005; Yakıcı ve diğ., 2010).

\subsubsection{Müzik Dili Prozodisi}

Yazı dili prozodisi ile aktarıma hazır hale gelen; bütün prozodi türleri için ortak olan ses, hece, kelime, vurgu, durgu, tonlama kavramları, konuşma dili ve anlam prozodisi ile şekillenirken, müzik dili prozodisi vasıtası ile müzik notaları ile birleştirilerek değerlendirilmekte ve konuşma prozodisinin melodik haline dönüşmektedir.

Müzik dili prozodisin açıklanabilmesi için bazı kavramların Türk Dili’ndeki kavramlarla özdeşleştirilerek açılanması; uyumun seste, hecede, sözcüklerde, sözcük gruplarında ve cümlelerde nasıl aranması gerektiği konusuna 1şık tutacaktır (Arel, 1997; Dinçer, 1992; Ergin, 2002; Güldaş, 1980; Güldaş, 2003; Hatipoğlu, 1988; İçelli, 2013; Karaağaç ve Yavuzer, 2011; Karahan, 2018; Korkmaz ve diğ., 2005; Say, 2005; Yakıcı ve diğ., 2010). 
Türkiye'de Okul Öncesi Eğitimi'nde En Çok Kullanılan Çocuk Şarkilarının Notalarının, Çocukların Yaşlarına Uygunluğunun Değerlendirilmesi Ve Şarkıların Türk Dili Prozodi Kurallarına Göre İncelenmesi

\subsubsection{Vurgu ve Durgu Kavramlarının, Prozodi Bağlamında, Ses, Hece, Sözcük, Sözcük Grubu ve Cümle İçindeki Yeri ve Önemi}

Ses kavramı, dillerin en küçük yapıtaşı iken, müzik dilindeki ses kavramı iki ya da daha fazla dilin birleştirilmesi ile sağlanabilmektedir. İnsan sesi, solunum yolu ve ses tellerinin ortak çalışması sonucunda oluşurken, enstrümanların sesleri, kendi yapılarına göre tasarlanmış sistemler aracıllı̆ı ile oluşan titreşimlerin sonucunda meydana gelmektedir.

Dilleri tanımlarken seslerden sonraki basamağı oluşturan hece kavramı, yan yana gelmiş, bir arada yazılan ve okunan sesleri tanımlamaktadır. Hem müzik notalarının ritmik yapıları ile hem konuşma dilindeki hece yapılarına göre ayrı ayrı tanımlanabilmektedir. Müzik dilinde yan yana gelen notalar da yazı ve konuşma dilindeki gibi bir bütünlük oluşturmaktadır. Prozodisini anlayabilmek için yazılı olanı doğru okuyarak konuşabilmek, konuşulanları ise müzik diline doğru kalıplarla ve sürelerle aktarabilmek gerekmektedir.

Varlıkları tanımlayan, tek heceden veya birkaç heceden oluşan anlamlı ses topluluklarına sözcük / kelime denmektedir. Nota karşılıklarına bakıldığında sözcüklerin anlamlarını destekleyen notalar ve ritimler bulunmaktadır. Fakat sözcükler her zaman yalın halleri ile bulunmamaktadır. Yapım ve çekim eklerinin önemi de sözcükler açısından oldukça büyüktür. Hecelerin doğal halleri de ek almış halleri hece bakımından incelendiğinde, hecelerin kısalık ve uzunlukları ayrı ayrı incelenmektedir. Heceler uzunluklarına göre notalarla değerlendirilmeli ve müzikteki karşılıklarının kelimeyi oluşturan heceler bazında orantılı dağıtılmış olması beklenmektedir.

Sözcük grupları genel anlamda değerlendirildiğinde alt başlıklarında tamlamaları ve birleşik sözcükleri görmekteyiz. Müzik dilinde de aynı şekilde Türk Dili'ndeki gibi ritim kalıpları bulunmaktadır. $\mathrm{Bu}$ ritim kalıpları müzik dilindeki seslerle birleşerek anlamlı gruplar oluşturmaktadır.

Cümlelerdeki vurgu sözcük ve sözcük grubu vurgusundan daha farklıdır. Vurgulu hece hem içinde olduğu kelimenin vurgusu haline gelmekte hem de cümlede vurgulanmak istenen sözcük veya sözcük grubunu (cümlenin ögesini) ön plana çıkartmaktadır. Örnek verecek olursak;

- Masmavi kelebekler biraz önce gökyüzünde uçuşuyordu.

Masmavi kelebekler sözcük grubudur ve kelebekler renkleri ile beraber vurgulanmıştır.

- Masmavi kelebekler biraz önce gökyüzünde uçuşuyordu.

Biraz önce sözcük grubudur ve zaman vurgulanmıştır

- Masmavi kelebekler biraz önce gökyüzünde uçuşuyordu.

Gökyüzünde sözcüğü ile yer belirten sözcük vurgulanmıştır.

- Masmavi kelebekler biraz önce gökyüzünde uçuşuyordu.

Uçuşuyordu sözcüğü ile gerçekleştirilen eylem vurgulanmıştır.

Yukarıdaki örnekten anlaşılacağı üzere cümle, duyguları, düşünceleri anlatmaya yarayan, bir araya gelmiş sözcükleri veya sözcük gruplarını tanımlamaktadır. Anlatım türlerinin en önemli 
unsurlarından bir tanesidir ve iletişim dilinin en küçük; ifade edilmek istenen duyguları ve düşüncelerin toparlayan ve akıcıllı̆ını sağlayan, bütünün oluşturulmasındaki yapı taşlarındandır. Müzik dili ile oluşturulan cümlelerle tamamen aynı amaca hizmet etmektedirler. Ritim ve seslerden oluşan melodiler ve melodilerin barındırdığı duygular düşünceler müzik cümlelerinin ortaya çıkmalarını sağlamaktadır.

Cümle vurgusu, sözlü anlatımda anlamın belirlenmesine yardım eder ve genellikle yüklem üzerinde bulunur. Vurgu, gerektiğinde belirtilmek istenen öge üzerine çekilebilir. Aynı kelimelerden oluşan ve öge dizilişi aynı olan cümlelerde, cümle vurgularının yerini değiştirerek farklı anlamlar elde etmek mümkündür.

Vurgulu hecelerin bulunabilmesi için kullanılan kurallar, Türk Dili'ndeki bütün sözcükler için aynı şekilde uygulanamamaktadır. İstisnalar için ise tekrar tekrar kural oluşturulması, kriterlerin çoğalması, vurgunun bulunması sürecinde kafa karıştırıcı olabilmektedir.

Bu kurallara alternatif olarak, sözcüklerdeki hecelerin, her birinin tek tek, vurguluymuş gibi tonlanması ve duyulan seslerdeki değişiklik yol gösterici olabilmektedir. Yani vurgunun deneme-yanılma yolu ile bulunabilmesi mümkündür. Vurgulanan hece, sözcügün anlam ya da konuşma dili prozodisini bozuyorsa vurgu o hecede değildir ve başka bir hece vurgulanarak söylenir. Eş sesli sözcüklerde de buna benzer bir durumla karşılaşılmaktadır. Örneğin, "atıl" sözcügünü bu anlamda değerlendirdiğimizde, ilk heceye vurgu verildiğinde işe yaramayan bir şey, ikinci heceye vurgu verildiğinde, bir işe birden bire girişildiği anlamı çıkarılmaktadır.

Vurgunun bulunduğu yer, öne çıkartılmak istenen sözcük ya da sözcük gruplarına göre belirlenebilmektedir. Tonlama yardımı ile güçlendirilmek istenen heceye vurgu verilebilmektedir. Genel anlamda vurgulanan hecenin değişmesi anlam değişikliğine; sözcük grubunda ya da cümlede vurgulanacak sözcügün seçimi cümlenin anlamında değişikliğe sebep olacağından, sözcüklerin, sözcük gruplarının ve cümlelerin dikkatle okunması gerekmektedir. (Arel, 1997; Dinçer, 1992; Ergin, 2002; Güldaş, 1980; Güldaş, 2003; Hatipoğlu, 1988; İçelli, 2013; Karaağaç ve Yavuzer, 2011; Karahan, 2018; Korkmaz ve diğ., 2005; Say, 2005; Yakıcı ve diğ., 2010).

Yazılı ve sözlü anlatımın müzikteki anlatım ile direk ilişkili olduğu göz önünde bulundurulduğunda anlatılmak istenenlerin aynı nüanslarla karşıya yansıtılmak istediği görülmektedir. Türkçede cümlelerin, sözcük gruplarının ve sözcüklerde, genel anlamda tüm düz yazı ve şiirlerde bulunan ve yazılı kaynakların seslendirilmesi esnasında anlamlandıran nüansların yani vurguların ve durguların hem yazılı hem de sözlü anlatım için de ortak olduğu anlaşılabilmektedir. Müzik dili prozodisinin uygunluk kriterlerini oluşturan en önemli unsurlardan olan vurgu ve durgu irdelenmesi gereken kavramlardandır. Bir diğeri ise müzik dilinde anlamlı sözcükler, sözcük grupları ve cümleler oluşturulmasına yardımcı olan notaların dizek üzerinde net görülen ses değişmeleridir. Notaların sürelerinin ve ses değişimlerinin, yazı ve konuşma dili ile uyumlu olmasını sağlamak için vurgunun öneminden, cümlelerin vurgusunu ve duraklarını anlatabilmek için de durgunun öneminden bahsedebiliriz. Bu kavramları ayrıntılı incelemek şarkıların prozodik açıdan değerlendirilebilmesi bakımından önem taşımaktadır (Arel, 1997; Dinçer, 1992; Ergin, 2002; Güldaş, 1980; Güldaş, 2003; Hatipoğlu, 1988; İçelli, 2013; Karaağaç ve Yavuzer, 2011; Karahan, 2018; Korkmaz ve diğ., 2005; Say, 2005; Yakıc1 ve diğ., 2010). 
Türkiye'de Okul Öncesi Eğitimi'nde En Çok Kullanılan Çocuk Şarkılarının Notalarının, Çocukların Yaşlarına Uygunluğunun Değerlendirilmesi Ve Şarkıların Türk Dili Prozodi Kurallarına Göre İncelenmesi

\subsubsection{Türk Dili'nde Durgu Kavramı}

Anlatımı daha akıcı ve etkili hale getirmek, dinleyenlerin ilgisini ve motivasyonunu korumak, anlatılmak istenen duygu ve düşünceleri karşı tarafa daha samimi şekilde aktarabilmek için doğru kullanılması gereken nüanslardan bir tanesi de durgudur.

Durmak, duraklamak, beklemek, ara vermek, susmak gibi anlamları bünyesinde barındıran bu kavramı cümlenin doğru yerlerinde kullanmak oldukça önemlidir. Türk Dili kurallarına göre sözcük ve / veya sözcük gruplarından önce ya da sonra kullanıldıkları görülmektedir. Fakat eseri yazan kişinin durağı nerede kullanmak istediği, kullanmış olduğu üslupla da alakalıdır. Konulduğu yerde anlamı değiştiren ya da duyguyu kuvvetlendiren durgular, imla işaretleri ya da alınan nefesler ile belirtilebilmektedir. Durgular, düz yazılarda da, şiirlerde de vurgularla birlikte kullanılmakta ve eserlerin yorumlanması denilen durumun meydana gelmesini sağlamaktadır (Arel, 1997; Dinçer, 1992; Ergin, 2002; Güldaş, 1980; Güldaş, 2003; Hatipoğlu, 1988; İçelli, 2013; Karaağaç ve Yavuzer, 2011; Karahan, 2018; Korkmaz ve diğ., 2005; Say, 2005; Yakıcı ve diğ., 2010).

\subsection{Türk Dili’ne Göre Müzik Prozodisi}

Türk Dili’nde yazılan şarkılarda prozodi incelemesi yapmak için kullanılan ögelerden önceki bölümlerde bahsedilmişti. Vurgu ve durgu kavramları, dilin yapısına uygun kullanılan bir anlatım yöntemi ile yazıldıktan sonra bestelenme aşamasına geçildiğinde konuşma ya da okuma dilindeki anlatım müzik diline yansıtılmış olacaktır. Dolayısıyla konuşurken ya da okurken kullanılan nüansların şarkıların notalarına da yansıtılması beklenmektedir.

Prozodi incelemesi yaparken karşımıza çıkan bir diğer kavram da hece uzunluğudur. Heceler oluşumlarına göre kısa ve uzun hece olarak adlandırılmaktadır. Heceleri aşağıdaki şekilde sinıflandırmak mümkündür;

- Bir sesli heceler: Yalnızca sesli harfler tek hece olarak kullanılabilmektedir. Bir tane sesli harften oluşan heceler kısa hecelerdir.

- İki sesli heceler: Sırası ile sesli-sessiz veya sessiz-sesli şeklinde bulunabilirler. İkinci sesi, sessiz olan heceler her zaman uzun hecelerdir. Türk Dili dışından, başka dillerden geçen, uzatılan sesli harflerin hecede yer alması durumunda, hece göründüğünden daha uzun okunur.

- Üç sesli heceler: Üç sesten oluşabilecek bütün heceler uzun hecedir. Başka dillerden, dilimize geçen uzun sesli harfler, hecenin daha da uzun okunmasına neden olmaktadır.

- Dört sesli heceler: Bir sesli ve üç sesli harften oluşan bu heceler uzun hecelerdir. Hece içerisinde uzun sesli harflerden birinin bulunması durumunda hece daha uzun okunacaktır.

Kısa ve uzun hecelerin gösterimleri ise , (.) ve (-) işaretleri ile yapılmaktadır. (.) kısa heceyi, () ise uzun heceyi belirtmektedir. 
Şarkıların Türk Dili prozodi kurallarına uyup uymadığı tespit edilirken, ilk olarak, her kelime, kelimeyi oluşturan heceler bazında değerlendirilir. Kelime içindeki hecelerin uzunlukları ile onlara karşılık gelen notaların orantılı olması beklenmektedir. Bu kuralın dışında kalan iki durum vardır.

- Vurgulu heceler, olması gerekenden daha uzun süreye sahip notaya ya da nota gruplarına karşılık gelebilir.

- Cümle sonlarındaki heceler, cümle bitişini anlatıyor olmaları sebebi ile daha uzun süreli notaya ya da nota gruplarına karşılık gelebilir.

Sözcük ve sözcük grubu vurgularının tespit edilmesinden sonra incelenmesi gereken bir diğer unsur olan durguların, müzik dili ile de belirtilip belirtilmediğidir. Kullanılan gereğinden uzun süreli notalar, sus işaretleri ve dizeğin üstlerine konulan virgüller, yani nefes yerleri durguları belirtebilmektedir.

Anlam bütünlügünün sağlanabilmesi, şarkıların Türk Dili’ne uygun olması ve kulağa hitap edebilmesi açısından bütün bu unsurlar birlikte değerlendirilmelidir. Fakat farklı üslupların, şive ya da ağızların kullanılması ve yorumcunun karakteristiği bu kuralların dışında kalabilecek durumlarla karşılaşmamıza neden olabilmektedir. Bu sebeple Türk Halk Müziği’nin prozodiye uygunluğuna bakılmamaktadır. Türk Sanat Müziği ve popüler şarkılar bu değerlendirmeye tabi olmaktadır (Arel, 1997; Dinçer, 1992; Ergin, 2002; Güldaş, 1980; Güldaş, 2003; Hatipoğlu, 1988; İçelli, 2013; Karaağaç ve Yavuzer, 2011; Karahan, 2018; Korkmaz ve diğ., 2005; Say, 2005; Yakıcı ve diğ., 2010).

\section{TÜRKIYE'DE OKUL ÖNCESİ EĞİTIMINDE KULLANILAN ÇOCUK ŞARKILARININ ÖZELLIKLLRİ VE PROZODIYYE UYGUNLUKLARININ ÖNEMİ}

Sanat dalları özellikle de müzik, çocukların özgüveni, sosyal çevreleri ile olan iletişimleri, yaratıcılıklarının gelişmesi, davranışlarının şekillenmesi ve öğrenme süreçleri açısından büyük önem taşımaktadır. Çocukların sözlü şarkılar dinleyerek bu şarkılara katılım sağlayarak daha verimli öğrenme süreçleri geçirdikleri bilinmektedir.

Sözlü şarkılar, eğitim-öğretim süreçleri için ne kadar önemli ise seçilen şarkıların çocukların yaşlarına; şarkının sözlerinin ve nota aralıklarının çocuğun gelişimsel yapısına uygunluğu da o kadar önemlidir.

Seçilen şarkıların sözlerinin anlamlı, olumlu ve çocukların yaşlarına uygun olmaları, doğru bilgileri aktarmakta kullanılabilmeleri gerekmektedir. Konuların sevgi ile alakalı, diğer konularla ilişkilendirilebilecek şekilde olması ve bu konuların masal, öykü ya da hikâyeler haline getirilerek, akılda kalıcılığın yaratıcı sözlerle desteklenmesi çocuk şarkılarında bulunması gereken en önemli özelliklerdendir.

Yapılan çalışmalarla, şarkıların nota aralığının re-la olarak seçilmesinin, çocuğun yaşı dolayısıyla, ses gelişimine uygun olduğu belirtmişsir. Si sesini de kapsayabilen bu aralığa diğer ince ya da kalın sesleri dahil etmek uygun olmayacaktır. Sesler arasında çok fazla atlama olmaması, sadece ikili, üçlü, dörtlü veya beşli aralıkların tercih edilmesi, çocukların şarkılara eşlik edebilmeleri bakımından önem taşımaktadır. 
Türkiye'de Okul Öncesi Eğitimi'nde En Çok Kullanılan Çocuk Şarkılarının Notalarının, Çocukların Yaşlarına Uygunluğunun Değerlendirilmesi Ve Şarkıların Türk Dili Prozodi Kurallarına Göre İncelenmesi

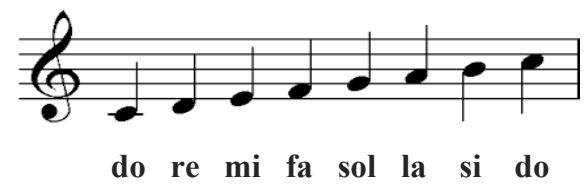

Şekil 1 Re-La ses aralığı

Çocukların, seçilen şarkıları severek söylenmesi ve tekrar etmesi sonucunda, yeni kelimeler öğrenmesi ve tekrarlar sayesinde bilgilerin kalıcı hale gelmesi, sözlerdeki anlama ve anlatım biçimine verilmesi gereken önemi belirtmektedir. Genelde anadilde yapılan bu çalışmalarda, dilin yapı özellikleri ve şarkıların prozodi bakımından düzgünlüğü dikkat edilmesi gereken durumlardandır. Dil kurallarının, kelimelerin telaffuzlarının yanlış öğretilmesi çocuğun anadil gelişimini olumsuz etkileyebilmektedir. Anlatım bozukluklarına engel olabilmek için kurulan cümlelerin kontrol edilmesi, vurguların yerli yerinde kullanılması ve doğru sesleri verebilecek bir kaynaktan, şarkıların doğru tonda söylenebilmesi amacı ile kulak çalışmalarının yapılması, çocukların birçok gelişim alanına, eşzamanlı olarak katkı sağlayacaktır (Artan, 2015; Başer, 2004; Dinçer, 1992; Gedikli, 2013; Modiri, 2012; Ömeroğlu ve diğ., 2006; Sığırtmaç, 2005;).

\section{6. ŞARKI ÖRNEĞİ - ARKADAŞIM EŞŞEK}




\section{ARKADAŞIM EŞŞEK}
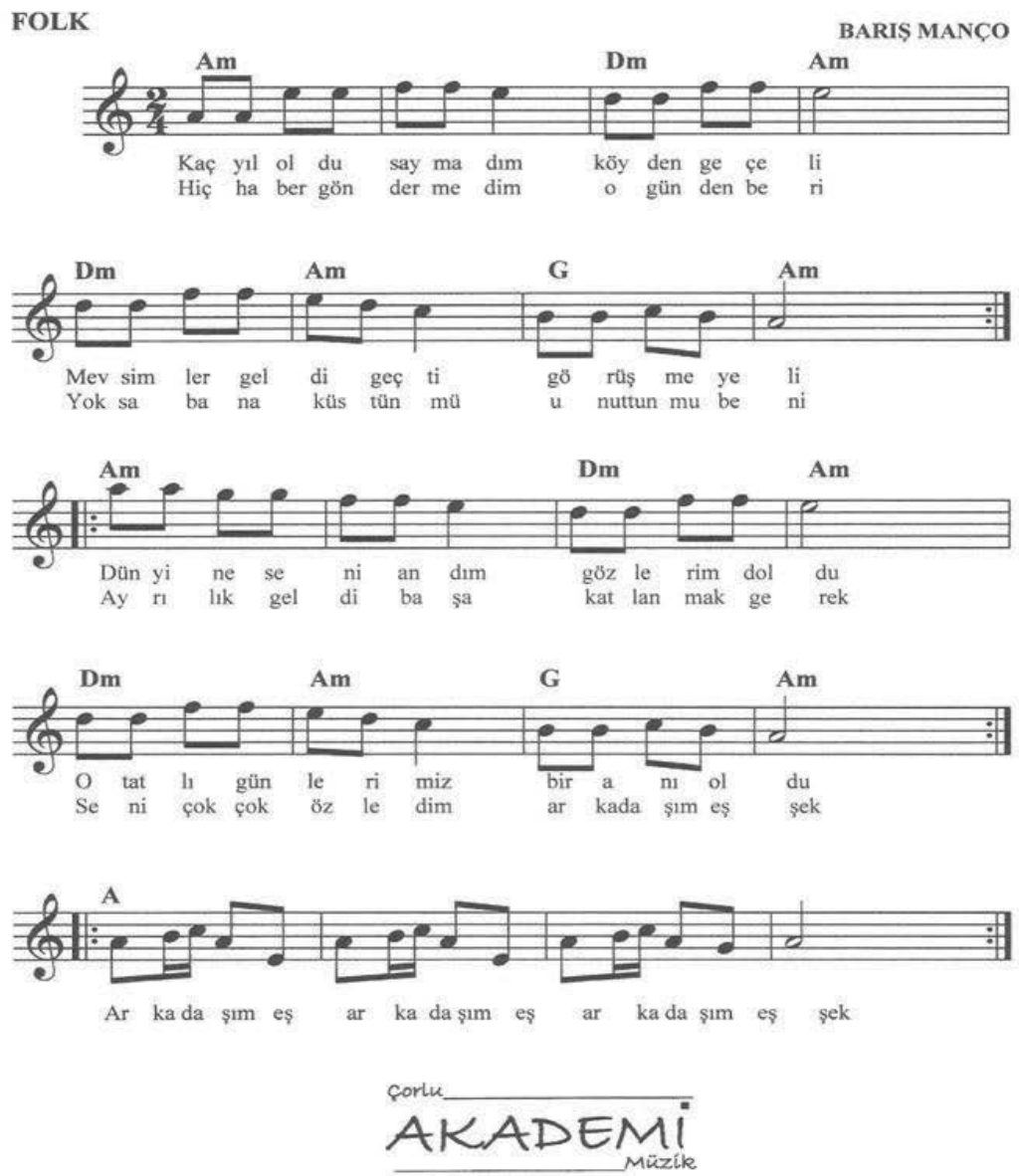

www. muzisyenindukkani.com

Şekil 2 Arkadaşım Eşşek (muzisyenindukkani.com)

\section{Şarkının Prozodi Bakımdan Değerlendirilmesi:}

Şarkının hecelerinin uzunlukları bakımından durumları sözcüklerin altlarında belirtilmiştir. () uzun heceleri, (.) kısa heceleri, kalın harfler ise vurguları göstermektedir.

$$
\text { KAÇ YIL OL-DU SAY-MA-DIM KÖY-DEN GE-ÇE-Lİ }
$$


Türkiye'de Okul Öncesi Eğitimi'nde En Çok Kullanılan Çocuk Şarkilarının Notalarının, Çocukların Yaşlarına Uygunluğunun Değerlendirilmesi Ve Şarkıların Türk Dili Prozodi Kurallarına Göre İncelenmesi

Türkçe sözcüklerde vurgu, istisnalar dışında, son hecede bulunmaktadır. Sıfat tamlamalarında ilk unsurda bulunan vurgu, olumsuzluk eklerinden önceki hecelerin de vurgu almasina neden olmaktadır. Dolayısıyla "kaç" kelimesi ve -du, -say, -den ve -li heceleri vurgulu hecelerdir.

"kaç" ve "yıl" kelimeleri tek heceli olduklarından, vurgu aranmaz. Kendi başlarına vurgulu duyulmaları mümkündür. Aynı zamanda sıfat tamlamasının ögeleri olmaları sebebi ile "kaç" kelimesinin daha vurgulu duyulması beklenebilir fakat notaların süreleri veya incelik kalınlıkları bakımından belirtilmediği görülmektedir -say ve -den heceleri de aynı durumda bulunmaktadır. -say hecesi, bir sonraki heceye karşılık gelen nota ile değerlendirildiğinde vurgusunun belirtilmediği fark edilmektedir. -den hecesindeki vurgu ise notalara hiç yansıtılmamıştır. -li hecesindeki vurgu belirtilmiştir. Notasının, bir önceki hecenin karşısına gelen notadan daha incedir.

-say ve -dım hecelerine bakıldığında süreleri uyumludur. -dım hecesi aynı zamanda cümle sonunu ve durguyu da belirtmektedir. Fakat -ma hecesinin karşısına gelen notasının süresi gereğinden fazladır. -li hecesinin 2'lik nota almasının sebeplerinden bir diğeri de, cümle sonunu ve durguyu göstermesidir.

Hecelerin ve notaların süreleri, birbirleri ile genel olarak uyumludur.

\section{MEV-SIM-LER GEL-Dİ GEÇ-Tİ GÖ-RÜŞ-ME-YE-Lİ}

Türkçe sözcüklerde vurgu, istisnalar dışında, son hecede bulunmaktadır. -me, -ma olumsuzluk ekleri, yanlarına geldikleri fiillerde vurgunun ekten önceki hecede bulunmasına sebep olmaktadır. Bu sebeplerden -ler, -di, -ti ve -rüş hecelerinde vurgu bulunmaktadır.

-ler hecesindeki vurgu, bir önceki hecenin karşısındaki notadan daha ince bir nota alması ile belirtilmiştir. İki farklı fiili anlatan "geldi" ve "geçti" kelimelerinin ikisi de vurgu alabilmektedir. Bu kelimelerdeki vurgular, hecelerdeki notaların, bir önceki hecelerden daha kalın nota alması ile ve sürelerinin diğer hecelere oranla daha fazla olması ile belirginleştirilmiş̧ir.

-rüş hecesindeki vurgu, hecenin diğer hecelerden daha ince bir nota alması ile belirtilmiştir. -li hecesinin uzun süreli bir nota olan 2'lik nota ile gösterilmesinin sebebi, cümle sonunu ve durguyu göstermesidir.

-gö hecesi, kısa ve vurgusuz bir hece olduğu halde 8'lik notaya karşılık gelmektedir.

Hecelerin ve notaların süreleri, genel olarak uyumludur.

\section{HİÇ HA-BER GÖN-DER-ME-DIN O GÜN-DEN BE-Rİ}

Türkçe sözcüklerde vurgu, istisnalar dışında, son hecede bulunmaktadır. -me, -ma olumsuzluk ekleri, yanlarına geldikleri fiillerde vurgunun ekten önceki hecede bulunmasına sebep olmaktadır. Edat grubunun vurgusu isim unsurunun üstünde, sıfat tamlamasının vurgusu ise ilk unsur üzerinde bulunmaktadır. "o günden beri” edat grubuna girmektedir. "o gün" ise sıfat tamlamasıdır. Bu sebeplerden -ber, -der, -den heceleri ve "o" sesi vurgu almaktadır. 
-ber, -der ve -den hecelerine karşılık gelen notalar, bir önceki hecelerden daha incedir. Vurguları belirtilmiştir. "o" tek sesli bir kelimedir ve tek sesli kelimelerin içinde vurgu aranmaz. Notasının kıyaslanabileceği hece bulunmamaktadır.

-ha ve -me heceleri kısa hecelerdir fakat uzun hecelerle aynı sürelerdeki notalara karşılık gelmişlerdir. Prozodi kurallarına uymadığı söylenebilmektedir.

-ri hecesinin 2'lik notaya karşıllık gelmesinin sebebi ise cümle sonunu ve durguyu belirtmesidir. Hecelerin ve notaların süreleri belirtilen durumlar dışında uyumludur.

\section{YOK-SA BA-NA KÜS-TÜN MÜ U-NUT-TUN MU BE-NI}

Türkçe sözcüklerde vurgu, istisnalar dışında, son hecede bulunmaktadır. Bağlaçlarda bulunan vurguyu bulmak için tonlama yöntemi ile heceler tek tek denendiğinde vurgunun genellikle ilk hecede olduğu gözlenmektedir. Soru anlamı yükleyen -mü eki ise vurgunun kendisinden önceki hecede bulunmasını sağlamaktadır.

-yok ve -na hecelerindeki vurgular, notaların süreleri ya da incelik kalınlığı bakımından belirtilmemiştir.-tün ve -ni hecelerindeki vurgular, heceye karşlık gelen notaların bir önceki notalardan daha kalın, -tun hecesindeki vurgu, heceye karşılık gelen notanın bir önceki notadan daha ince olması ile gösterilmiştir.

-ni hecesinin 2'lik nota ile gösterilmiş olmasının başka bir sebebi de cümle sonunu ve durguyu gösteriyor olmasıdır.

"bana" ve "unuttun mu" kelimelerinin kendi içlerindeki prozodileri, notalarının süreleri bakımından değerlendirildiğinde uyumlu görülmemektedir.

Hecelerin ve notaların süreleri belirtilen durumlar dışında uyumludur.

DÜN Yİ-NE SE-NI AN-DIM GÖZ-LE-RIM DOL-DU

Türkçe sözcüklerde vurgu, istisnalar dışında, son hecede bulunmaktadır. Zarflarda vurgu genellikle son hecede bulunmamaktadır "yine" kelimesinin heceleri, tonlama yardımı ile denendiğinde, vurgunun, ilk hecede olduğu tespit edilebilmektedir.

-yi ve -rim hecelerindeki vurgular, hecelerin notalarının, bir sonraki hecelerden daha ince olması ile, -ni, -dım ve -du hecelerindeki vurgular, hecelerinin karşılığındaki notaların, bir sonraki hecelere karşılık gelen notalardan daha kalın olması ile belirtmektedir.

-du hecesinin 2'lik nota ile gösterilmesinin bir diğer sebebi de cümle sonunu ve durguyu belirtmesidir.

Hecelerin ve notaların süreleri genel olarak birbiri ile uyumludur.

O TAT-LI GÜN-LE-Rİ-MIZ BİR A-NI OL-DU

Türkçe sözcüklerde vurgu, istisnalar dışında, son hecede bulunmaktadır. Sıfat tamlamalarında ise vurguyu ilk unsur almaktadır. "o tatlı günlerimiz" ve "bir anı" tamlamaları ise sıfat 
Türkiye'de Okul Öncesi Eğitimi'nde En Çok Kullanılan Çocuk Şarkalarının Notalarının, Çocukların Yaşlarına Uygunluğunun Değerlendirilmesi Ve Şarkıların Türk Dili Prozodi Kurallarına Göre İncelenmesi

tamlamalarıdır. Bu sebeplerden "o" ve "bir" kelimeleri ile -lı ve -du hecelerinde vurgu bulunmaktadır.

"o" ve "bir" tek heceli kelimeler olduğundan, kelime içinde vurgu aranmamaktadır. Fakat vurgulanmak isterlerse cümle içinde vurgulu okunabilmektedirler. -lı hecesine karşılık gelen nota, bir önceki heceye karş1lık gelen notadan daha ince olduğundan ve süre olarak, kısa hece olduğu halde uzun hece ile aynı süreye karşılık geldiğinden, vurgusu belirtilmiştir.

-dım hecesinin 4'lük, -du hecesinin 2'lik nota ile gösterilmesinin başka bir sebebi de cümle sonunu ve durguyu göstermeleridir.

Cümle genelinde, kısa hece uzun hece ve vurgu ayrımı yapılmadığından, kelimeler, prozodi kurallarına uygun değildir.

\section{AY-RI-LIK GEL-Dİ BA-ȘA KAT-LAN-MAK GE-REK}

Türkçe sözcüklerde vurgu, istisnalar dışında, son hecede bulunmaktadır. Cümledeki tüm kelimelerin son hecelerinde vurgu bulunmaktadır.

-lık hecesi uzun bir hecedir, kendinden önceki hecelere bakıldığında hecenin süresinin kısa hecelerden daha uzun olması beklendiği halde 8'lik nota ile gösterilmiştir. Heceye karşılık gelen nota, kendinden önceki hecenin notasından daha kalın olduğundan vurgu belirtilmiştir denilebilmektedir.

-di hecesinin nota süresinin 8'lik nota ve uzun hecelerle aynı tartımda olması vurgunun belirtildiğini göstermektedir.

-şa hecesinin karşısına gelen notanın bir önceki heceye karşılık gelen notadan daha kalın olması ve karşısındaki notanın 4'lük nota olması hem vurguyu hem de durguyu göstermektedir.

-mak hecesinin karşısına gelen notasının, önceki hecelerin karşısına gelen notalardan daha ince olması vurguyu belirtmektedir. Uzun hecelerin 8'lik notalara karşıllk geldiği değerlendirilirse, vurgulu hecenin tartım olarak daha uzun süreli bir nota ile belirtilmesinin gerektiği de görülebilmektedir.

-rek hecesine karşılık gelen notanın, önceki hecelerden daha kalın olması ve hecenin 2'lik nota ile gösterilmesi hem vurguyu, hem durguyu, hem de cümle sonunu belirtmektedir.

Cümle içerisinde, hecelerin uzunluk-kısalığı ve vurguların uygulanışı yeterince dikkate alınmamıştır.

\section{SE-NI ÇOK ÇOK ÖZ-LE-DIM AR-KA-DA-ŞIM EŞ-ŞEK}

Türkçe sözcüklerde vurgu, istisnalar dışında, son hecede bulunmaktadır. Tekrar gruplarında ise her sözcüğün vurgusu kendine aittir. Bu sebeple -ni, -dim, -şım ve -şek heceleri ile "çok çok" tekrar grubunda vurgu bulunmaktadır.

-ni hecesindeki vurgu, notasının süresi ya da incelik kalınlığı bakımından belirtilmemiştir. 
"çok çok" kelime grubunun unsurları tek heceli olduğundan, kelime içlerinde vurgu aranmamaktadır. Fakat şarkı söylenirken notaları vurgulu olarak söylenebilmektedir.

-dim hecesinin karşı1lığındaki nota, bir önceki hecenin karşısına gelen notadan daha kalın ve notasının süresi 4'lük nota olduğundan vurgu belirtilmiştir. Aynı zamanda bu nota cümle sonunu ve durguyu da göstermektedir.

-şım hecesinin karşısındaki nota, kendisinden önceki hecelerden daha incedir. Vurgunun belirtildiği söylenebilmektedir.

-şek hecesinin karşısındaki nota bir önceki heceden daha kalın ve uzun sürelidir. 2'lik notaya karşılık gelmiş olması hem vurguyu hem cümle sonunu hem de durguyu belirtmiştir.

Cümlede genel olarak hecelerin uzunluk kısalıkları ile notaların süreleri uyumludur.

AR-KA-DA-ŞIM EŞ AR-KA-DA-ŞIM ŞEK AR-KA-DA-ŞIM EŞ-ŞEK

Şarkının nakaratında unvan niteliği taşıyan sözcük bulunduğu halde, unvan grubunun unsurları yer değiş̧irdiğinden bu gruplar aslında birleşik isimlerdir. Türkçede, birleşik isimlerde vurgu sonda bulunmaktadır.

“eş” ve "şek" kelimeleri tek heceli olduklarından, kelime içlerinde vurgu aranmamaktadır. Bu kelimeler kendi başlarına vurgulu okunabilmektedirler.

-şek hecesine karşılık gelen nota, önceki heceden daha incedir. Notanın süresi ise 2'lik nota değerindedir. Hem vurgu hem durgu hem de cümle sonu belirtilmiştir.

Şarkının nota aralığının, çocukların seslerine uygunlukları bakımından değerlendirilmesi durumunda re-la aralığının dışında seslerle karşılaşılmaktadır. Şarkının nota aralığındaki sesler okul öncesi çocukların sesleri bakımından daha ince kalabilmektedir.

Konu olarak arkadaş sevgisinin ve özlem kavramının hikâyeleştirilerek anlatılması çocuklar açısından olumlu kazanım sağlamaktadır. Şarkının prozodisinde bulunan hatalar, icra esnasında düzeltilebilmektedir.

\section{Sonuç}

Müziğin çocuklar için önemi birçok bağlamda değerlendirilebilmektedir. Çocukların hem fiziksel hem ruhsal gelişimine olan katkısı yadsınamaz bir gerçektir. Anadil gelişimin direk etkisi ve kendini ifade etme becerisi ile öz güven kazanımı sağlaması, çocuğun, bulunduğu çevrelerde kendini gerçekleştirmesine olanak sağlamaktadır.

Çocukların eğitim-öğretiminde müziğin kullanılmasının en önemli sebeplerinden bir tanesi ise müziğin yani melodinin ve sözlerin, çocuğun aklında kalıcı etki bırakmasıdır. Kalıcılık özelliği, eğitim-öğretimde kullanılan şarkıların, çocukların yaşlarına uygun ve doğru bilgileri aktarıyor olmasının gereğini vurgulamaktadır.

$\mathrm{Bu}$ durumda şarkıların yalnızca öğretici olmasını beklemek, diğer unsurlarını görmezden gelmek, çocuk şarkılarında bulunması gereken özelliklerin birçoğunun ihmaline sebep olacaktır. 
Türkiye'de Okul Öncesi Eğitimi'nde En Çok Kullanılan Çocuk Şarkılarının Notalarının, Çocukların Yaşlarına Uygunluğunun Değerlendirilmesi Ve Şarkıların Türk Dili Prozodi Kurallarına Göre İncelenmesi

İncelenmesi gereken ve şarkıların değerlendirilmesinde dikkate alınan unsurları sıralamak gerekirse sırası ile aşağıdaki gibidir.

1. Şarkıların sözlerinin doğruyu, gerçeği yansıtması ve somut olması.

2. Şarkının sözlerinde anlatım bütünlüğünün sağlanması, Türk Dili’nin yapısına ve kurallarına uygunluğu

3. Şarkının nota aralıklarının okul öncesi çocuğunun gelişimsel yapısına dolayısıyla re-la ses aralığına uygunluğu

4. Şarkının sözlerinin, kelime bazında değerlendirildiğinde, hecelerin süreleri ile karşılarına gelen notaların sürelerinin orantılı olması

5. Anlatımın akıcılığının sağlanması bakımından ahengin, yani vurguların ve durguların şarkının yapısına uygun kullanılmış olması.

Çocuklara yönelik şarkı bestelenirken önce sözlerin hikâyeleştirilmesi, daha sonra sözlere uygun beste yapılması halinde, bütün bu unsurların birbirleri ile uyum içinde olması mümkün kılınacaktır.

Sanatta Yeterlik tezinde incelenmiş olan fakat makalede yer almayan Ali Babanın Çiftliği (Alpöge, 2006: 52), Karga ile Tilki (Alpöge, 2006:41), Annem (Alpöge, 2006: 43), Arı (Çetin, 2015: 129) şarkıları da Arkadaşım Eşek şarkısının incelendiği yöntemle incelenmiş ve genel olarak aşağıdaki sonuçlarla karşılaşılmıştır.

- Okul öncesi çocukları için uygun olmayan sözlerle, doğruluk payı, açıklayıcılık özelliği olmayan anlatımlarla ve kendi içinde anlam bütünlüğü sağlanmamış konular,

- Argo sözcükler,

- Ritme uygunluk sağlanması açısından, hece doldurmak için kullanılan ve tamlama gruplarının vurgularını bozan "bir" kelimeler,

- Gereksiz tekrarlarla,

- Durgu, vurgu, ahenk eksiklikleri ile karşılaşı1mıştır.

Vurguların bulunmasına dair hazırlanmış olan kuralların işaret etmiş olduğu sonuçlara, hecelere tonlama yolu ile vurgu verilerek de değerlendirme yapmak mümkündür. Türk Dili'nin yapıs1 sebebi ile vurgu kurallarına dahil edilemeyen kelimeler için tonlama yöntemi beste yaparken de şarkıların daha doğru hazırlanabilmesine yardımcı olmaktadır.

Genel olarak ortaya çıan sonuçlardan, melodinin önce hazırlanıp üstüne söz yazılmasından ya da yabancı dilden müzik kültürümüze uyumlanmış melodilerden kaynaklanmış olabileceği ihtimali düşünülebilir. Çocukların gelişimsel sürecine uygun nota aralığına uygun notaların kullanılması, anadilin, yani Türk Dili’nin yapısal özellikleri göz ardı edilmemesinin gereği görülmektedir. Kültürümüzde kalıcılığı olan ve nesilden nesle aktarılan bu şarkıların, kültürümüzü temsil etme özelliği de dikkate alınmalıdır. Günümüzde, çocuk şarkılarının birçoğunda karşılaşılan bu aksaklıklar, çocukların, ileri yaşlarda prozodi hatalı şarkıların farkına varmaması sonucunu doğurmaktadır. Yazı dilinde her ne kadar kurallara dikkat ediliyor olsa da okuma ve konuşma dilinin kurallara uygun kullanılmaması, dilimizin, yıllar içinde yozlaşmasına da sebep olacaktır. 
Okul öncesi çocuklarına yönelik şarkıların, müzik kitaplarının, müzikli çocuk oyunlarının daha özenli hazırlanması, anadilin özenli kullanılması gerekmektedir. Eğitim-öğretim sürecinde öğretmenlerin, şarkı seçimlerinde bilinçli olması, müziğin, okul öncesi çocuğunun gelişiminde daha verimli kullanılmasını sağlayacaktır.

\section{KAYNAKÇA}

\section{Kitaplar}

Adorno, T. W. (2011). Kültür Endüstrisi Kültür Yönetimi. N. Ülner, M. Tüzel, E. Gen. (Çev). (6. Bask1). İstanbul: İletişim Yayınları.

Alpöge, G. (2006). Çocuk ve Müzik. (1. Baskı). İstanbul: Bu Yayınevi.

Altıntaş, E. ve Çamur, D. (2005). Beden Dili Sözsüz İletişim. (2. Baskı). Ankara: Mentis Yayıncilik.

Arel, H. S. (1997). Prozodi Dersleri. (2. Baskı). İstanbul: Pan Yayınc1lı.

Artan, İ. (2015). Okul Öncesi Dönemde Müzik Eğitimi. (1. Baskı). Ankara: Hedef Yayınc1lık.

Campbell, J. (2006). Illkel Mitoloji. G. K. Emiroğlu (Çev). (3. Baskı). Ankara: İmge Kitabevi.

Candan, E. (2008). Türkler’in Kültür Kökenleri. (7. Bask1). İstanbul: Sınır Ötesi Yayınları.

Cook, N. (1999). Müziğin ABC'si. T. Doğan (Çev). (1. Baskı). İstanbul: Kabalcı Yayınevi.

Çetin, Ç. Ç. (2015). Okul Öncesinde Etkinliklerle Müzik Eğitimi. (3. Baskı). Ankara: Kök Yayınc1lik

Dinçer, İ. (1992). Çocuk Gelişimi ile İlgilenenler İçin Müzik El Kitabı. (1. Baskı). İstanbul: Ya Pa Yayınları.

Ergin, M. (2002). Üniversiteler İçin Türk Dili. (1. Bask1). İstanbul: Bayrak Basım/Yayım/Tanıtım.

Erol, A. (2009). Müzik Üzerine Düsünmek. (1. Baskı). İstanbul: Bağlam Yayınları.

Gedikli, E. (2013). Eğitsel Ritmik Dinamik Etkinliklerle Müzik. (1. Baskı). Bursa: Ezgi Kitabevi.

Güldaş, S. (2003). Vurgu ve Vurgulamaları ile Türk Musikısinde Prozodi. (1. Baskı). İstanbul: Saadet Güldaş.

Günay, E. (2011). Müzik Sosyolojisi. (2. Baskı). İstanbul: Bağlam Yayınları.

Güvenç, B. (2010). İnsan ve Kültür. (1. Baskı). İstanbul: Boyut Yayıncılık.

Hatipoğlu, A. (1988). TRT Karşılaştırmalı ve Uygulamalı Türk Musıkisi Prozodisi. (1. Baskı). 
Türkiye'de Okul Öncesi Eğitimi'nde En Çok Kullanılan Çocuk Şarkılarının Notalarının, Çocukların Yaşlarına Uygunluğunun Değerlendirilmesi Ve Şarkıların Türk Dili Prozodi Kurallarına Göre İncelenmesi

Ankara: TRT Müzik Dairesi Yayınları.

Karaağaç, G. ve Yavuzer, H. (2011). Yükseköğretimde Türk Dili ve Kompozisyon. (1. Baskı). Ankara: Okutman Yayıncılık.

Karahan, L. (2018). Türkçede Söz Dizimi. (25. Baskı). Ankara: Akçağ Yayınları.

Kaygısız, M. (2017). Müzik Tarihi. (2. Baskı). İstanbul: Kategori Yayıncılık.

Khan, S.I. (2001). Müzik Insan ve Evren Arasındaki Köprü. K. H. Ökten, T. Ökten (Çev). (2.Bask1). İstanbul: Arıtan Yayınevi.

Korkmaz, Z., Ercilasun, A. B., Gülensoy, T., Parlatır, İ., Zülfikar, H., Birinci, N. (2005). Türk Dili ve Kompozisyon. (1. Baskı). Bursa: Ekin Yayınevi.

Modiri, I. G. (2012). Okul Öncesi Müzik Eğitiminde Genel Yaklaşımlar. (1. Baskı). Ankara: Elhan Kitap Yayın Dağıtım.

Oskay, Ü. (2011). Illetişimin ABC'si. (6. Baskı). İstanbul: Der Yayınları.

Ömeroğlu, E., Ersoy, Ö., Şahin, F. T., Kandır, A., Turla, A. (2006). Müziğin Okul Öncesi Eğitiminde Kullanılması. (2. Baskı). Ankara: Kök Yayıncılık.

Say, A. (2005). Müzik Sözlügü̈. (2.Baskı). Ankara: Müzik Ansiklopedisi Yayınları.

Sığırtmaç, A. D. (2005). Okul Öncesi Dönemde Müzik Eğitimi. (1. Baskı). İstanbul: Kare Yayınları.

Şentürk, R. (2016). Müzik ve Kimlik. (1. Bask1). İstanbul: Küre Yayınları.

Wulf, C. (2009). Tarihsel Kültürel Antropoloji. Ö. D. Sarısoy (Çev). Ankara: Dipnot Yayınları.

Yakıc1, A., Yücel, M., Doğan, M., Yelok, S. (2010). Üniversiteler İçin Türk Dili ve Kompozisyon Bilgileri. (6. Baskı). Ankara: Gazi Kitabevi.

Yıldırım, A. ve Şimşek, H. (2018). Sosyal Bilimlerde Nitel Araştırma Yöntemleri. (11. Baskı). Ankara: Seçkin Yayıncılık.

Yıldırım, V. ve Koç, T. (2011). Müzik Felsefesine Giriş. (5. Baskı). İstanbul: Bağlam Yayıncilik.

\section{Süreli Yayınlar}

Başer, F. A. (2004). Müziğin Okul Öncesi Dönemde Çocuk Gelişimine Katkısı. Sakarya Üniversitesi Eğitim Fakültesi Dergisi. 8. Sakarya. 1-10.

İçelli, E. N. (2013). Dünya Müziği ve Türk Müziği Açısından Prozodi Meselesinin Tarihsel Süreci ve Gelişimi. Kültür Evreni. S.17, 118-121. 
Kol, S. (2011). Erken Çocuklukta Bilişsel Gelişim ve Dil Gelişimi. Sakarya Üniversitesi Eğitim Fakültesi Dergisi. C.21, S.21, 1-21.

\section{Diğer Kaynaklar}

Artan, İ. (1993). Anaokuluna Devam Eden 54-77 Aylı Çocuklara Seslerle Illgili Becerilerin Kazandırllmasında Müzik Uygulamalarının Etkisinin İncelenmesi. Doktora Tezi. Ankara: Hacettepe Üniversitesi. Sağlık Bilimleri Enstitüsü.

Güldaş, S. (1980). Türkçe'de Vurgu ve Musikımizin Sözlü Eserlerinde Prozodik Uygulamalar. Doktora Tezi. İstanbul: İstanbul Üniversitesi. Sosyal Bilimler Enstitüsü.

\section{İnternet Kaynakları}

https://muzisyenindukkani.com.cutestat.com/ 01.06.2016 